\title{
Effect of Enterococcus faecium EF 55 on morphometry and proliferative activity of intestinal mucosa in broilers infected with Salmonella Enteritidis
}

\author{
Zuzana Ševčíková ${ }^{1}$, Ján Blanár ${ }^{2}$, Andrea Lauková3 \\ Viera Revajová ${ }^{1}$, Viola Strompfová ${ }^{3}$, Mikuláš Levkut ${ }^{1}$ \\ ${ }^{1}$ Institute of Pathological Anatomy, \\ University of Veterinary Medicine and Pharmacy, Komenského 73, 04181 Košice, Slovak Republic, \\ ${ }^{2}$ Imuna s.r.o., 08222 Šarišské Michal’any, Slovak Republic \\ ${ }^{3}$ Institute of Animal Physiology, Slovak Academy of Science, 04001 Košice, Slovak Republic \\ zuzana.sevcikova@uvlf.sk
}

Received: April 7, 2016

Accepted: September 6, 2016

\begin{abstract}
Introduction: The present study aimed to investigate the effect of Enterococcus faecium EF55 on chickens, as well as its influence on proliferative activity of epithelial intestinal cells after infection with Salmonella enterica serovar Enteritidis phage type 4 (SE PT4). Moreover, the length and area of duodenal and jejunal villi of the birds were examined. Material and Methods: A pool of 80 birds was divided randomly into four groups. Probiotic group (EF) and Salmonella + probiotic group (EFSE) received E. faecium EF55 ( $10^{9} \mathrm{CFU}-3$ g per group/day) during $22 \mathrm{~d}$. Salmonella group (SE) and EFSE group were infected with Salmonella Enteritidis PT4 $\left(10^{8} \mathrm{CFU}\right.$ in $0.2 \mathrm{~mL}$ PBS) in a single dose per os on day four of the experiment, whereas control birds (C group) received only $0.2 \mathrm{~mL}$ of PBS on that day. Samples were taken on the $4^{\text {th }}$ and $18^{\text {th }}$ day post infection. Results: Supplementation of feed with E. faecium EF 55 confirmed its selective antibacterial activity against SE PT4. The chickens infected with SE PT4 and fed E. faecium EF55 supplemented diet showed increased proliferative activity of enterocytes in the jejunum in both samplings. Applied probiotic strain demonstrated positive impact on intestinal morphometry in the jejunum of both non-infected groups and in Salmonella-infected chickens. In the latter group, the beneficial effect of E. faecium EF 55 was manifested by more efficient tissue turnover in the jejunum.
\end{abstract}

Keywords: chickens, probiotic, Salmonella, intestinal morphometry, proliferative activity of enterocytes.

\section{Introduction}

Salmonellosis is one of the most prevalent zoonoses in the world. The disease is spread through the digestive tract after per os infection. Several representatives of the Salmonella genus are responsible for morphological alteration in intestinal mucosa. One of the positive properties of some probiotic microbiota including E. faecium EF55 is their antimicrobial effect due to the production of bacteriocins and competitive exclusion of pathogenic bacteria on the mucosal surface $(7,13)$.

The nutritional value of diets used to feed chickens has traditionally been evaluated by growth performance and nutrient digestibility. Furthermore, the direct correlation between morphology of the intestine, digestion, and absorption efficiency is well documented (16). Enterocyte proliferation in the vertebrate small intestine is generally restricted to the crypts at the basis of the villi. The proliferation of enterocytes in chicken intestinal epithelium takes place not only in the villous crypts as in the case of mammals, but also along the villi (15). In poultry the positive immunostaining of proliferating cell nuclear antigen (PCNA) indicates the proliferation of enterocytes both in the crypt and along the villi (15).

In vivo, the inhibitory effect of E. faecium EF55 against different bacteria, including Salmonella Enteritidis was demonstrated in our previous study (8). Recently, beneficial influence of EF55 strain on the 
production of intestinal mucin has been shown in chickens (9). On the other hand, the effect of E. faecium EF 55 on intestinal morphology in birds infected with pathogenic bacteria is still not known. Therefore, the aim of this study was to clarify the effect of E. faecium EF55 on the proliferation activity of enterocytes and morphometric parameters of small intestine in chickens, after their experimental infection with Salmonella enterica serovar Enteritidis PT4.

\section{Material and Methods}

Animals. A total of 80 one-day-old hybrid ISABrown female chicks were randomly divided into four equal groups. The chicks were kept in isolation in floor pens of $1 \mathrm{~m}^{2}$ per group on wood shaving that was changed daily during the experiment. The pens were lit continuously. The temperature was maintained at a value required for the age of the birds $\left(32^{\circ} \mathrm{C}\right.$ in week 1 and then reduced by about $2^{\circ} \mathrm{C}$ weekly). Water and feed were available ad libitum.

The chicks were divided into four equal groups: C (control), SE (Salmonella enterica serovar Enteritidis phage type 4), EF (E. faecium EF55), EFSE (E. faecium EF55 + Salmonella Enteritidis PT4). The experimental procedure was as follows: C group (control) received placebo $-0.2 \mathrm{~mL}$ of PBS on day four of the experiment, groups EF and EFSE received E. faecium EF55 (10 ${ }^{9} \mathrm{CFU}-3 \mathrm{~g}$ per group/day) during 22 days, and groups SE and EFSE were infected with Salmonella enterica serovar Enteritidis PT4 $\left(10^{8} \mathrm{CFU}\right.$ in $0.2 \mathrm{~mL}$ of PBS) in a single dose per os on day 4 of the experiment. Chickens were anaesthetised with an intraperitoenal injection of xylazine (Rometar 2\% SPOFA, Czech Republic) and ketamine (Narkamon $5 \%$, SPOFA, Czech Republic) at doses of $0.6 \mathrm{~mL}$ and $0.7 \mathrm{~mL} / \mathrm{kg}$ b.w., respectively. After laparotomy, blood was collected into heparinised tubes $(10-20 \mathrm{U} / \mathrm{ml}$ in PBS, Zentiva, Czech Republic) by cardiac punction. The samples for serum were frozen and stored at $-20^{\circ} \mathrm{C}$. During the following necropsy the samples for immunostaining against PCNA and for micromorphometric and microbiological analyses were collected (Table 2). Faeces, caecum, and small intestine were sampled on day 9 (4 days post infection with SE PT4) and on day 22 (18 day post infection - dpi) of the experiment (Table 1).

EF55 strain preparation, microbial counts. Experimental infection was performed using Salmonella enterica serovar Enteritidis phage type 4 (SE PT4, kindly provided by Dr. Spišák from the Institute of Veterinary Medicine, Brno, Czech Republic) in a single dose $10^{8} \mathrm{CFU}$ in $0.2 \mathrm{~mL}$ of PBS per os. Enterococcus faecium EF55, probiotic and bacteriocin-producing strain, was isolated and characterised in the Institute of Animal Physiology, Slovak Academy of Sciences, Košice, Slovakia (14) and was added to animals' diet of EF and EFSE groups in the dose $10^{9} \mathrm{CFU} / \mathrm{mL} /$ (3 g per group/day) for 22 days. Briefly, the strain was cultivated in MRS broth (Merck, Germany) at $37^{\circ} \mathrm{C}$ to achieve final cells concentration of $10^{9}$ per $\mathrm{mL}$. Fifteen millilitres of the broth culture and $15 \mathrm{~mL}$ of freeze-dried milk Laktino (as protecting substance for dry freezing) were mixed and stored in the fridge at $-60^{\circ} \mathrm{C}$ for $24 \mathrm{~h}$. Freezedrying was performed using MicroModulyo (Thermo, USA). To differentiate EF55 strain from the other enterococci, it was labelled by rifampicin (14). Freezedrying was repeated to have enough mass for the experiment. Bacterial counts were determined by the standard microbiological method using selective media according to ISO. M-Enterococcus agar (Difco, USA) was used to enumerate enterococci. EF55 strain was counted on M-Enterococcus agar enriched with rifampicin (14). It was also confirmed by PCR (17). To detect the presence of Salmonella, the samples were pre-treated in Rappaport-Vassiliadis medium (Merck, Germany) and then spread on brilliant green agar (Becton and Dickinson, USA). The bacteria were cultivated at $37^{\circ} \mathrm{C}$ for $24-48 \mathrm{~h}$ and expressed in $\mathrm{CFU} / \mathrm{g} \pm \mathrm{SD}$.

Proliferating cell nuclear antigen (PCNA) assay. Samples were taken from the cranial part of the jejunum on the $4^{\text {th }}$ and $18^{\text {th }} \mathrm{dpi}$, fixed in $10 \%$ neutral buffered formalin, and embedded in paraffin. PCNA immunostaining was carried out on the $5 \mu \mathrm{m}$ tissue sections with commercial Animal Research Kit (ARK) according to the included protocol (DAKO, Denmark). The kit contained monoclonal mouse PCNA antibody (Clone PC 10, DAKO, Denmark) and all the necessary components (peroxidase block, streptavidin HRP, blocking reagent, biotinylation reagent, and DAB tablets). Negative controls were obtained by omitting the primary antibodies.

Quantification of positive cells in the jejunum. The cells in the jejunum were counted in the villus epithelium and lamina propria from the villus basal lamina (which coincides with the upper crypt end) toward the villus apex. Twenty appropriate areas were chosen at random from each of these sites. Measurements were taken under a light microscope at $400 \times$ magnification. The positively stained cells within each randomly selected area were counted using a calibrated ocular graticule LTD $0.25 \mathrm{~mm} \mathrm{Id} \mathrm{x} \mathrm{Grd}$ (Electronmicroscopy, UK). The appearance of positive enterocytes was expressed in numbers per square millimeter.

Morphometrical analysis. Dudoenal and jejunal samples (height and area of the villus) collected from five chickens on the $4^{\text {th }}$ and $18^{\text {th }}$ dpi were analysed. In order to measure the height and the areas of the villi, the samples were microphotographed (Nikon LABOPHOT 2 with a camera adapter DS Camera Control Unit DS-U2, $4 \times$ ) and then the NIS-Elements version 3.0 softver (Laboratory Imaging, Czech Republic) was used. The heights of the villi were measured from the basal region, which corresponded to 
the higher section of the crypts, to the apex $(\mu \mathrm{m})$. Total villus area included villus length and breadth $\left(\mu \mathrm{m}^{2}\right)$. The data were finally exported to MS Excel and subsequently statistically analysed by ANOVA with post-hoc Tukey multiple comparison test. The differences between the mean values for groups of chickens were considered significant when $\mathrm{P}<0.05$.

\section{Results}

E. faecium EF55 effectively colonised caecum; its count on the $4^{\text {th }}$ dpi was higher $(\mathrm{P}<0.01)$ in EF group than in EFSE group.

Reduction of Salmonella counts $(\mathrm{P}<0.05)$ was found in EFSE group compared with SE group on the $4^{\text {th }}$ dpi. Similarly, there was a decrease $(P<0.01)$ in enterococci in EFSE group in comparison with EF group on the $4^{\text {th }}$ dpi. The counts of enterococci in faeces were higher $(\mathrm{P}<0.05)$ in $\mathrm{EF}$ group than in control birds on the $18^{\text {th }}$ dpi.
The tendency to increase the height of the duodenal and jejunal villi in EF group was found in both tissue samplings in comparison with the results obtained in the other groups. The difference $(\mathrm{P}<0.05)$ was found in the jejunum of SE group compared to chickens of EF group on the $4^{\text {th }}$ dpi (Table 2). the differences were found between EF and SE groups $(\mathrm{P}<0.001)$ in the villus parameter (Table 3$)$ of both tissue collections in the jejunum. A decrease in jejunal villus parameter was found between EF and EFSE group $(\mathrm{P}<0.05)$ in the first tissue collection. In the second one, the area of jejunal villi was smaller in SE group compared to that in chickens of $\mathrm{EF}$ group $(\mathrm{P}<0.001)$ as well as to control chickens $(\mathrm{P}<0.01)$.

In the first collection, the density of PCNA positive cells (Table 4$)$ was lower $(\mathrm{P}<0.01)$ in SE and higher $(\mathrm{P}<0.001)$ in EF and EFSE groups than in control chickens. In the second collection, the number of positive cells was higher in EF and EFSE groups $(\mathrm{P}<0.001)$ than in control and SE group $(\mathrm{P}<0.001)$.

Table 1. Bacterial counts in faeces and caecum in $\log 10 \mathrm{CFU} / \mathrm{g}$ (mean $\pm \mathrm{SD}$ ) in feed after application of freeze-dried Enterococcus faecium EF 55 and oral infection with Salmonella Enteritidis PT4

\begin{tabular}{|c|c|c|c|c|c|}
\hline & & & Faeces & & \\
\hline Microorganism & sampling & control & EF & $\mathrm{SE}$ & EFSE \\
\hline \multirow{3}{*}{ Enterococcus sp. } & 0 & $5.79 \pm 1.94^{\mathrm{c}}$ & & & \\
\hline & $4 \mathrm{dpi}$ & $8.46 \pm 1.42$ & $8.40 \pm 0.73$ & $7.27 \pm 0.61$ & $6.63 \pm 0.21^{\mathrm{d}}$ \\
\hline & $18 \mathrm{dpi}$ & $4.04 \pm 0.0^{\mathrm{a}}$ & $5.82 \pm 0.76^{\mathrm{b}}$ & $5.23 \pm 0.15$ & $5.62 \pm 0.65$ \\
\hline \multirow[t]{3}{*}{ E. faecium EF 55} & 0 & & $\mathrm{nt}$ & & \\
\hline & $4 \mathrm{dpi}$ & $\mathrm{nt}$ & $2.03 \pm 0.70^{\mathrm{a}}$ & $\mathrm{nt}$ & $3.07 \pm 0.76^{\mathrm{b}}$ \\
\hline & $18 \mathrm{dpi}$ & $\mathrm{nt}$ & $3.45 \pm 1.02$ & $\mathrm{nt}$ & $3.13 \pm 0.39$ \\
\hline \multirow{3}{*}{$\begin{array}{l}\text { Salmonella } \text { Enteritidis } \\
\text { PT4 }\end{array}$} & 0 & & np & & \\
\hline & $4 \mathrm{dpi}$ & $\mathrm{np}$ & $\mathrm{nt}$ & $4.80 \pm 1.08$ & $4.29 \pm 0.25$ \\
\hline & $18 \mathrm{dpi}$ & $\mathrm{np}$ & $\mathrm{nt}$ & $3.60 \pm 0.99$ & $6.10 \pm 0.0$ \\
\hline \multirow[b]{2}{*}{ Microorganism } & & & Caecum & & \\
\hline & sampling & control & $\mathrm{EF}$ & SE & EFSE \\
\hline \multirow{3}{*}{ Enterococcus sp. } & 0 & & $6.89 \pm 1.94$ & & \\
\hline & $4 \mathrm{dpi}$ & $9.08 \pm 0.34$ & $8.50 \pm 0.58^{c}$ & $7.62 \pm 0.43$ & $6.24 \pm 1.17^{d}$ \\
\hline & $18 \mathrm{dpi}$ & $5.35 \pm 0.21$ & $6.49 \pm 1.69$ & $5.76 \pm 1.8$ & $5.26 \pm 0.9$ \\
\hline \multirow{3}{*}{ E. faecium EF 55} & 0 & $\mathrm{nt}$ & & & \\
\hline & $4 \mathrm{dpi}$ & $\mathrm{nt}$ & $3.87 \pm 0.26$ & $\mathrm{nt}$ & $3.18 \pm 0.37$ \\
\hline & $18 \mathrm{dpi}$ & $\mathrm{nt}$ & $2.82 \pm 0.43^{\mathrm{a}}$ & $\mathrm{nt}$ & $4.70 \pm 0.61^{\mathrm{b}}$ \\
\hline \multirow{3}{*}{$\begin{array}{l}\text { Salmonella Enteritidis } \\
\text { PT4 }\end{array}$} & 0 & $\mathrm{np}$ & & & \\
\hline & $4 \mathrm{dpi}$ & np & $\mathrm{nt}$ & $5.11 \pm 0.65^{\mathrm{a}}$ & $4.69 \pm 0.0^{\mathrm{b}}$ \\
\hline & $18 \mathrm{dpi}$ & $\mathrm{np}$ & $\mathrm{nt}$ & $3.60 \pm 0.99$ & $\mathrm{np}$ \\
\hline
\end{tabular}

nt- not tested; np-not present;

Means \pm SD with different superscript letters in the same line differ significantly at $\mathrm{P}<0.05 \mathrm{a}-\mathrm{b}, \mathrm{P}<0.01 \mathrm{c}-\mathrm{d}$, and $\mathrm{P}<0.001 \mathrm{e}-\mathrm{f}$

Table 2. The height of chicken small intestinal villi $(\mu \mathrm{m})$ in control and experimental groups treated with Enterococcus faecium EF 556 and Salmonella Enteritidis PT4

\begin{tabular}{|c|c|c|c|c|}
\hline \multirow[b]{2}{*}{ Group } & \multicolumn{2}{|c|}{ First collection $-4 \mathrm{dpi}$} & \multicolumn{2}{|c|}{ Second collection $-18 \mathrm{dpi}$} \\
\hline & Duodenum & Jejunum & Duodenum & Jejunum \\
\hline $\mathrm{C}$ & $950.0 \pm 188.3$ & $874.9 \pm 115.6$ & $1129.0 \pm 78.11$ & $1050.0 \pm 109.9$ \\
\hline $\mathrm{EF}$ & $976.4 \pm 71.22$ & $951.0 \pm 69.83^{\mathrm{a}}$ & $1258.0 \pm 150.5$ & $1067.0 \pm 82.27$ \\
\hline SE & $840.6 \pm 171.0$ & $815.9 \pm 103.1^{\mathrm{b}}$ & $1100.0 \pm 161.9$ & $1019.0 \pm 64.77$ \\
\hline EFSE & $947.4 \pm 104.3$ & $835.7 \pm 95.17$ & $1126.0 \pm 116.9$ & $1026.0 \pm 107.2$ \\
\hline
\end{tabular}

Means \pm SD with different superscript letters in the same column differ significantly at $\mathrm{P}<0.05 \mathrm{a}-\mathrm{b}$ 
Table 3. Area of chicken jejunal and duodenal villi $\left(\mu \mathrm{m}^{2}\right)$ in control and experimental groups treated with Enterococcus faecium EF 556 and Salmonella Enteritidis PT4

\begin{tabular}{|c|c|c|c|c|}
\hline \multirow[b]{2}{*}{ Group } & \multicolumn{2}{|c|}{ First collection -4 dpi } & \multicolumn{2}{|c|}{ Second collection $-18 \mathrm{dpi}$} \\
\hline & Duodenum & Jejunum & Duodenum & Jejunum \\
\hline $\mathrm{C}$ & $93418.0 \pm 28037.0$ & $88107.0 \pm 11828.0$ & $162670.0 \pm 32710.0$ & $142182.0 \pm 17227.0^{\mathrm{e}}$ \\
\hline $\mathrm{EF}$ & $98907.0 \pm 20788.0$ & $108961.0 \pm 21620.0^{\mathrm{a}, \mathrm{c}}$ & $167336.0 \pm 27776.0$ & $146046.0 \pm 15771.0^{\mathrm{a}}$ \\
\hline SE & $89083.0 \pm 36803.0$ & $74192.0 \pm 11766.0^{\mathrm{b}}$ & $157135.0 \pm 45570.0$ & $112190.0 \pm 21386.0^{\mathrm{b}, \mathrm{f}}$ \\
\hline EFSE & $91926.0 \pm 15841.0$ & $83476.0 \pm 28353.0^{\mathrm{d}}$ & $158459.0 \pm 41666.0$ & $133971.0 \pm 21937.0$ \\
\hline
\end{tabular}

Means \pm SD with different superscript letters in the same column differ significantly at $\mathrm{P}<0.001 \mathrm{a}-\mathrm{b}$;

$\mathrm{P}<0.05 \mathrm{c}-\mathrm{d}$, and $\mathrm{P}<0.01 \mathrm{e}-\mathrm{f}$

Table 4. Number of PCNA positive cells in chicken jejunum $\left(\mu \mathrm{m}^{2}\right)$ in control and experimental groups treated with Enterococcus faecium EF 556 and Salmonella Enteritidis PT4

\begin{tabular}{lll}
\hline Group & First collection -4 dpi & Second collection -18 dpi \\
\hline C & $5386.0 \pm 843.5^{\mathrm{a}, \mathrm{e}}$ & $5093.0 \pm 761.6^{\mathrm{a},}$ \\
\hline $\mathrm{EF}$ & $7031.0 \pm 921.4^{\mathrm{b}, \mathrm{d}}$ & $7822.0 \pm 616.2^{\mathrm{b}, \mathrm{d}}$ \\
\hline SE & $3883.0 \pm 698.9^{\mathrm{c}, \mathrm{f}}$ & $4567.0 \pm 799.9^{\mathrm{c}}$ \\
\hline EFSE & $7295.0 \pm 1307.0^{\mathrm{b}, \mathrm{d}}$ & $7888.0 \pm 948.82^{\mathrm{b}, \mathrm{d}}$ \\
\hline
\end{tabular}

Means \pm SD with different superscript letters in the same column differ significantly at $\mathrm{P}<0.001 \mathrm{a}-\mathrm{b}, \mathrm{c}-\mathrm{d}$, and $\mathrm{P}<0.01 \mathrm{e}-\mathrm{f}$

\section{Discussion}

E. faecium $\mathrm{EF} 55$ is able to reduce the populations of pathogenic intestinal microflora, probably by its bacteriocin substance (14). Inhibitory effect of E. faecium EF55 was demonstrated by reducing SE PT4 counts in the caecum. Influence of E. faecium EF55 on the intestinal microflora may result in decreasing bacterial impact on intestinal barrier, which in turn reduces the presence of toxins possibly associated with changes in intestinal morphology. Reduction phenomenon of pathogenic bacteria colonisation could be one of the causes of increasing intestinal proliferative activity in the intestine. In order to establish a firm relation between administration of E. faecium EF55 and proliferation of mucous epithelium we evaluated villus length and its absorption area. Administration of E. faecium EF55 in feed of non-infected birds resulted in an increase in the height of villi in jejunum on the $4^{\text {th }}$ dpi. Our finding is consistent with earlier reports demonstrating an increase in jejunal villi after application of probiotic microbiota, e.g. Lactobacillus spp. (1), Bacillus subtilis var. natto (16), and Bifidobacterium termophilum (2). On the other hand, administration of EF55 strain to chickens infected with $S$. Enteritidis did not influence the height of villi. Similar results in the current trial were obtained in the case of evaluation of jejunal villi area in chickens treated with E. faecium EF55. The beneficial effect on the villus area was observed in both samplings. The differences in the villus length and its area between the duodenum and jejunum support the importance of the jejunum as a site of nutrients digestion (5). Moreover, in the current study, it has been well documented that an increase in villus length and surface area in all examined groups is agedependent.

On the basis of higher differences of both parameters among chicken groups in the jejunum in relation to the duodenum we have chosen to study proliferative activity in the jejunum. In chickens, this intestinal region also reveals higher mucosal turnover than the duodenum (11), indicating higher renewal of epithelial cells in this region in relation to other intestinal segments.

The current study showed increased frequency of proliferative activity of intestinal epithelial cells in chickens fed the diet supplemented with E. faecium EF55 and infected with SE. It suggests that E. faecium EF55 positively influenced the proliferation of enterocytes and can contribute to earlier regeneration of intestinal epithelium, which is in correlation with increased villus height and area in chickens of that group. Beneficial effect of E. faecium EF55 on integrity of intestinal mucus was also supported by a significant increase in proliferative activity of epithelial cells in the jejunum of non-infected birds; it was in correlation with increased villus height and area in chickens of that group. On the other hand, decreased proliferative activity of enterocytes in the chickens infected with 
Salmonella Enteritidis could be caused by inflammatory process and regressive changes, including cell death of intestinal epithelial cells (7). Earlier it was reported that specific strains of probiotic microbiota produce short-chain fatty acids (6). These acids contribute to the stimulation of proliferation of normal crypt cells, enhancing healthy tissue turnover and maintenance (10). Many authors continue to discuss the effects of probiotic microbiota on integrity of the intestinal epithelium in chickens, e.g. the efficacy of excluding important pathogens such as Salmonella which has been highly variable (12). Moreover, probiotic microbiota can improve performance when compared to the diets without antimicrobial growth promoters (3).

In conclusion, E. faecium EF55 with its antibacterial properties is able to increase absorptive surface of jejunal mucus and enterocyte proliferation along the jejunal villi. Beneficial effect of probiotic microbiota revealed improvement of intestinal architecture and tissue turnover in the jejunum in Salmonella-infected chickens. Further studies are needed to characterise the interactions between E. faecium EF55 influenced bacterial microflora and jejunal mucus.

Conflict of Interests Statement: The authors declare that there is no conflict of interests regarding the publication of this article.

Financial Disclosure Statement: The study was supported by Slovak Research and Developmental Agency under contract No. APVV-0302-11 and VEGA Slovakia, Grant, No. 1/0313/12.

Animal Rights Statement: The experimental protocol was approved by the Ethics Commission of the University of Veterinary Medicine and Pharmacy. Animal handling was performed according to the acceptance and approval of the State Veterinary and Food Administration.

\section{References}

1. Awad W.A., Ghareeb K., Böm J.: Effect of addition of a probiotic micro-organism to broiler diet on intestinal mucosal architecture and electrophysiological parameters. Anim Physiol Anim Nutr 2009, 94, 486-494.
2. Chichlowski M., Croom J., Mcbridge B.W., Havestein G.B., Koci M.D.: Metabolic and physiologic impact of probiotics or direct-fed-microbials on poultry: a brief review of current knowledge. Int J Poult Sci 2007, 6, 694-704.

3. Farria Filho D.E., Torres K.A., Faria D.E.: Probiotics for broiler chickens in Brazil. Systematic review and meta-analysis. Brazil J Poult Sci 2006, 8, 89-98.

4. Herich R., Kokinčáková T., Lauková A., Levkutová M.: Effect of preventive application of Enterococcus faecium EF55 on intestinal mucosa during salmonellosis in chickens. Czech J Anim Sci 2010, 55, 42-47.

5. Iji P.A., Saki A.A., Tivey D.R.: Intestinal structure and function of broiler chickens on diets supplemented with a mannan oligosaccharide. J Sci Food Agr 2001, 81, 1186-1192.

6. Kaur N., Gupta A. K.: Application of inulin and oligofructose in health and nutrition. J Biosci 2002, 27, 703-714.

7. Knodler L.A, Finlay B.B.: Salmonella and apoptosis: to live or let die? Microb Infect 2001, 3, 1321-1326.

8. Levkut M., Pist J., Lauková A., Revajová V., Herich R., Ševčíková Z., Strompfová V., Szabóová R., Kokinčáková T.: Antimicrobial activity of Enterococcus faecium against Salmonella enteritidis in chicks. Acta Vet Hungarica 2009, 57, 13-24.

9. Levkut M. Jr., Revajová V., Lauková A., Ševčíková Z., Spišáková V., Faixová Z., Levkutková M., Strompfová V., Levkut M.: Leukocytic responses and intestinal mucin dynamics of broilers protected with Enterococcus faecium EF55 and challenged with Salmonella Enteritidis. Res Vet Sci 2012, 93, 195-201.

10. MacFarlane G.Y., Steed H., MacFarlane S.: Bacterial metabolism and health - related effects of galacto-oligosaccharides and other prebiotics. J Appl Microbiol 2008, 104, 305-344.

11. Peek H.W., Van der Klis J.D., Vermeulen B., Landman W.J.M.: Dietary protease can alleviate negative effects of a coccidiosis infection on production performance in broiler chickens. Anim Feed Sci Technol 2009, 150, 151-159.

12. Revolleledo L., Ferreira A.J.P., Mead G.C.: Prospects in Salmonella control: competitive exclusion, probiotics, and enhancements of avian intestinal immunity. J Appl Poult Res 2006, 16, 341-351.

13. Ribeiro A.M.L., Vogt L.K., Canal C.W., Cardoso M.R.I., Labres R.V., Streck A.F., Bessa M.C.: Effect of prebiotics and probiotics on the colonization and immune response of broiler chickens challenged with Salmonella Enteritidis. Brazil J Poult Sci 2007, 9, 193-200.

14. Strompfova V., Lauková A., Mudroňová D.: Effect of bacteriocin-like substance produced by Enterococcus Faecium EF55 on the composition of avian gastrointestinal microflora. Acta Vet Brno, 2003, 72, 559-564.

15. Uni Z., Platin R., Sklan D.: Cell proliferation in chicken intestinal epithelium occurs both in the crypt and along the villus. J Comp Physiol B 1998, 168, 241-247.

16. Yamauchi K.: Review on chicken intestinal villus histological alterations related with intestinal function. J Poult Sci 2002, 39, 229-242.

17. Woodford N., Egelton M.C., Morrison D.: Comparison of PCR with phenotypic methods for the speciation of enterococci. Plenum Press, New York 1997, 47, 405-409. 